\title{
Improving the Dielectric Properties of High Density Polyethylene by Incorporating Clay-Nanofiller
}

\author{
Ossama E. Gouda', Sohair F. Mahmoud'2, Ahmed A. El-Gendy ${ }^{3}$, Ahmed S. Haiba' \\ ${ }^{1}$ Electrical Department, Faculty of Engineering, Cairo University, Giza, Egypt \\ ${ }^{2}$ High Voltage Metrology Lab, National Institute of Standards (NIS), Giza, Egypt \\ ${ }^{3}$ Nanotechnology and Nanometrology Lab, National Institute of Standards (NIS), Giza, Egypt \\ Email: Prof ossama11@yahoo.com, sohairfakhry@hotmail.com, dr aboad2000@yahoo.com, \\ eng haiba@yahoo.com
}

Received 10 September 2014; revised 5 October 2014; accepted 30 October 2014

Academic Editor: Jiann-Yang (Jim) Hwang, Materials Science and Engineering, Michigan Technological University, USA

Copyright @ 2014 by authors and Scientific Research Publishing Inc.

This work is licensed under the Creative Commons Attribution International License (CC BY). http://creativecommons.org/licenses/by/4.0/

(c) (i) Open Access

\section{Abstract}

Polymer nanocomposites have been used for various important industrial applications. The preparation of high density polyethylene composed with Na-montmorillonite nanofiller using melt compounding method for different concentrations of clay-nanofiller of $0 \%, 2 \%, 6 \%, 10 \%$, and $15 \%$ has been successfully done. The morphology of the obtained samples was optimized and characterized by scanning electron microscope showing the formation of the polymer nanocomposites. The thermal stability and dielectric properties were measured for the prepared samples. Thermal gravimetric analysis results show that thermal stability in polymer nanocomposites is more than that in the base polymer. It has been shown that the polymer nanocomposites exhibit some very different dielectric characteristics when compared to the base polymer. The dielectric breakdown strength is enhanced by the addition of clay-nanofiller. The dielectric constant $\left(\varepsilon_{r}\right)$ and dissipation factor (Tan $\delta$ ) have been studied in the frequency range $200 \mathrm{~Hz}$ to $2 \mathrm{MHz}$ at room temperature indicating that enhancements have been occurred in $\varepsilon_{r}$ and Tan $\delta$ by the addition of clay-nanofiller in the polymer material when compared with the pure material.

\section{Keywords}

Polymer Nanocomposites, High Density Polyethylene, Dielectric Breakdown, Dielectric Constant, Dissipation Factor 


\section{Introduction}

Polymers play an important role for many applications due to their unique properties which can be classified as heat sensitive, flexible, electrically insulating, amorphous, or semi-crystalline materials. For that reason, polymers are the most commonly used dielectrics because of their reliability, availability, ease of fabrications, and low cost. The selection of the proper dielectric polymer for a desired application depends on the requirements and operating conditions of the applied system [1]. The electrical properties of polymers can be improved by the addition of inorganic nano-fillers to the polymers forming new materials called polymer nanocomposites (PNC). Polymer nanocomposites are composite materials having several wt\% of inorganic particles of nanometer dimensions homogeneously dispersed into their polymer matrix. PNC with better dielectric and electrical insulation properties are slowly emerging as excellent functional materials for dielectrics and electrical insulation application and the term "nanodielectrics" for such materials is increasingly becoming popular. Although the technology of addition of fillers to polymers to enhance a particular dielectric property has been in existence for several decades [2]-[4], the effect of filler size on the dielectric behaviour of the polymer composites has not been understood fully. It is with the advent of nanotechnology leading to the availability and commercialization of nanoparticles that polymer nanocomposite technology started to gain momentum. Polymer nanocomposites have been found to exhibit enhanced physical, thermal, mechanical, and dielectric properties when compared to the traditional polymer materials especially at low nano-filler concentrations (1\% - 10\%) [5]-[7]. However, it is only recently that the dielectric properties of such polymer nanocomposites were looked into and limited research results demonstrate very encouraging dielectric properties for these materials. Irrespective of the type of base polymer material (thermoplastic or thermoset), significant enhancements in several physical properties, like thermal conductivity (with conducting fillers) or dielectric properties like resistivity, permittivity, dissipation factor, dielectric strength, tracking and partial discharge resistant characteristics (with insulating fillers) were observed when compared to similar properties in traditional neat polymers [8]-[10]. These observations were mainly attributed to the unique properties of nanoparticles and the large interfacial area in polymer nanocomposites [11]-[13].

The present work focuses on the dielectric properties of polyethylene (PE) nanocomposites. Polyethylene is one of the thermoplastic polyolefin which is traditionally one of the most widely used polymer classes with applications in structural, textile, and packaging industries, and their nanocomposites have found multiple applications for the same uses. This paper shows the preparation and characterization of high density polyethylene composed with Na-montmorillonite clay-nanofiller (HDPE/clay) with different concentrations of clay-nanofiller as $0 \%, 2 \%, 6 \%, 10 \%$ and $15 \%$. Then the dielectric properties, such as dielectric constant, dissipation factor, dielectric breakdown, and insulation resistance, of the prepared samples will be discussed and compared to the base polymer material.

\section{Experimental Work}

\subsection{Materials}

HDPE with melt flow rate of $0.75 \mathrm{~g} / \mathrm{min}$ and density of $960 \mathrm{~kg} / \mathrm{m}^{3}$ is chosen as the base polymer material for the current study. It was manufactured by the International Company for Manufacturing Plastic Products. Sodium montmorillonite clay K10 (MMT) was acquired from fluka chemika company. Hexadecyl Trimethyl Ammonium Bromide, modifier or surfactant material, was obtained from Merck KGaA, Darmstadt, Germany.

\subsection{Modification of Clay}

The preparation of polymer/clay nanocomposites with good dispersion of clay layers within the polymer matrix is not possible by physical mixing of polymer and clay particles. It is not easy to disperse nanolayers in most polymers due to the high face to face stacking of layers in agglomerated tactoids and their intrinsic hydrophilisity which make them incompatible with hydrophobic polymers. The intrinsic incompatibility of hydrophilic clay layers with hydrophobic polymer chains prevents the dispersion of clay nanolayers within polymer matrix and causes to the weak interfacial interactions. Modification of clay layers with hydrophobic agents is necessary in order to render the clay layers more compatible with polymer chains, and result in a larger interlayer spacing. In addition, modification process improves the strength of the interface between the inorganic clay and the polymer matrix. So, sodium montmorillonite (Na-MMT) clay was modified with the compatiblizer of Hexadecyl Trimethyl Ammonium Bromide [14]. 
$100 \mathrm{~g}$ of clay was dispersed into $1000 \mathrm{ml}$ of methanol solvent and placed on hot plate with magnetic stirrer to allow continuous stirring for 2 hours. On the other hand, $100 \mathrm{~g}$ of hexadecyl trimethyl ammonium bromide was dissolved in $500 \mathrm{ml}$ of methanol. Then the solution was added to clay dispersion. The stirring continued for 72 hours. After that, the modified clay was filtered and collected. Finally the filtrate was dried in a vacuum oven at $70^{\circ} \mathrm{C}$ for 6 hours [15].

\subsection{Preparation of HDPE/Clay Composites}

The concentrations of modified clay-nanofiller were added as $0 \%, 2 \%, 6 \%, 10 \%$, and $15 \%$ into the base polymer material. HDPE/clay nanocomposites were prepared by melt compounding method (master batch method) using twin screw extruder (TSE) at zones temperature $163^{\circ} \mathrm{C}, 167^{\circ} \mathrm{C}$, and $167^{\circ} \mathrm{C}$, for Zone 1 , Zone 2 , and Zone 3 respectively. The screw speed was maintained at $30 \mathrm{rpm}$. After extrusion, the dried pellets of nanocomposites were preheated using Morgan Press Injection unit at $160^{\circ} \mathrm{C}$ for $30 \mathrm{~min}$ and injected to produce test samples with dimensions $7.5 \mathrm{~cm} \times 7.5 \mathrm{~cm} \times 0.25 \mathrm{~cm}$ for dielectric measurements [15]. The prepared samples are referred to in this paper as HDPE 0\% (pure material), HDPE 2\%, HDPE 6\%, HDPE 10\%, and HDPE 15\%.

\subsection{Characterization of HDPE/Clay Composites}

The prepared samples were characterized by the scanning electron microscope (SEM). SEM is a type of electron microscope that produces images of a sample by scanning it with a focused beam of electrons. The electrons interact with atoms in the sample, producing various signals that can be detected and that contain information about the sample's surface topography and composition. The scanning electron microscope images were carried out by using SEM, model Quanta 250 FEG (Field Emission Gun) attached with EDX unit (Energy Dispersive $\mathrm{X}$-ray Analyses), with accelerating voltage $30 \mathrm{kV}$, magnification $14 \times$ up to 1,000,000×, and a resolution of $1 \mathrm{~nm}$.

Thermal stability was measured by using thermo gravimetric analysis (TGA). TGA experiments were done by a shimadzu TA-50 thermal analyzer using scanning rate of $5^{\circ} \mathrm{C} / \mathrm{min}$ under $\mathrm{N} 2$ with $20 \mathrm{ml} / \mathrm{min}$ flow rate, from room temperature to $600^{\circ} \mathrm{C}$.

\subsection{Dielectric Properties}

Dielectric breakdown refers to a rapid reduction in the resistance of an electrical insulator when the voltage applied across it exceeds the breakdown voltage. Dielectric breakdown measurements were performed using AC Dielectric Test Set. The samples were sandwiched between two electrodes and tested at room temperature under an ac voltage ramp of $750 \mathrm{~V} / \mathrm{sec}$. The ac voltage was increased with a rate of $750 \mathrm{~V} / \mathrm{Sec}$ until breakdown occurred.

Dielectric constant is called relative permittivity which is a parameter that indicates the relative charge storage capability of dielectrics in the presence of an electric field. The used instrument is an Agilent E4980A LCR meter with dielectric sample holder. The equivalent parallel capacitance $\left(\mathrm{C}_{\mathrm{p}}\right)$ was measured directly by the LCR meter, then the dielectric constant is calculated as shown below in the results section.

Dissipation factor is called loss tangent or Tan $\delta$. It represents the energy loss in the dielectrics and it is preferred to be smaller for insulation materials. It was measured directly by an Agilent E4980A LCR meter with dielectric sample holder in the frequency range $200 \mathrm{~Hz}$ to $2 \mathrm{MHz}$ at room temperature.

Also, insulation resistance was measured directly by LCR meter at the same conditions.

\section{Results and Discussion}

\subsection{Scanning Electron Microscopy (SEM)}

The morphology of the SEM images for HDPE with 2\% clay, 6\% clay, 10\% clay, and 15\% clay composites is shown in Figures 1-4 respectively. Each sample has two images with different magnifications. All SEM images for all samples revealed that, clay was dispersed in polymer matrix very well and there wasn't any accumulation of clay-nanofiller in it. An important observation is that the thickness of clay content is still in nano-size range (1 - $100 \mathrm{~nm}$ ). This means that the samples were successfully prepared.

\subsection{Thermal Analysis}

The thermal stability of the prepared samples was measured using thermo-gravimetric analyzer (TGA). In this 


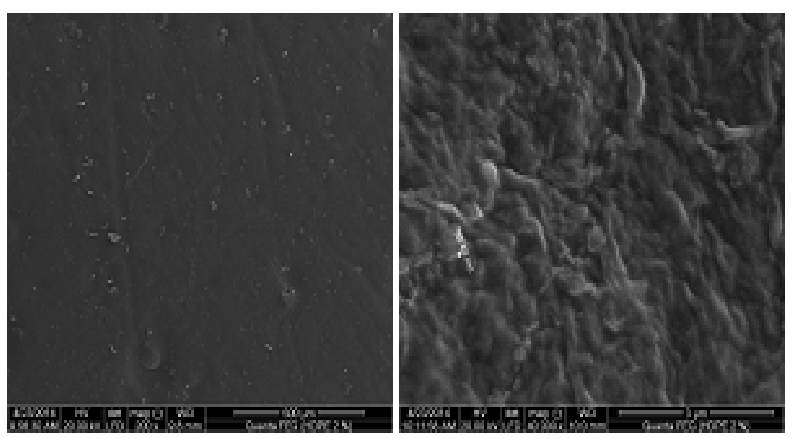

Figure 1. SEM images for HDPE $2 \%$ sample at $(200 \times \& 40,000 \times)$ magnifications.

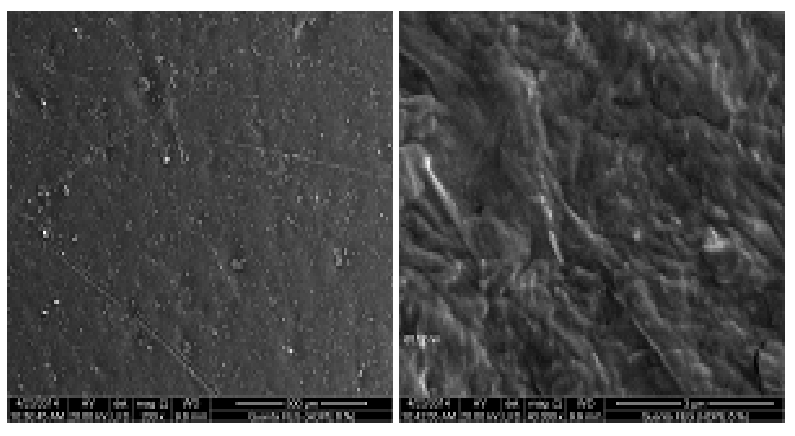

Figure 2. SEM images for HDPE 6\% sample at (200× \& 40,000×) magnifications.
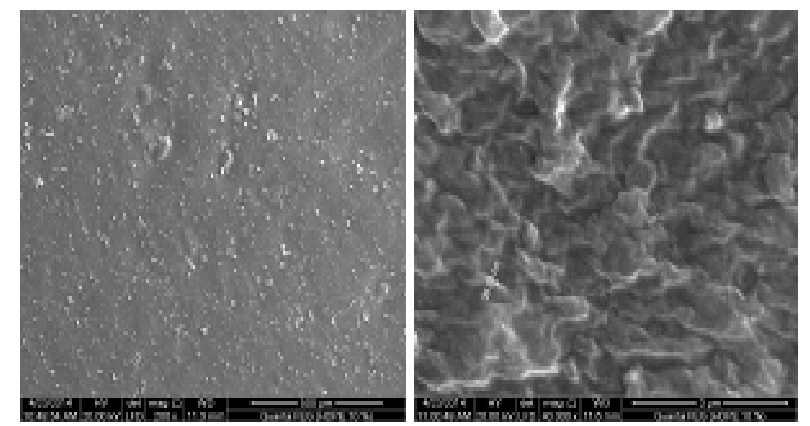

Figure 3. SEM images for HDPE $10 \%$ sample at $(200 \times \&$ 40,000×) magnifications.

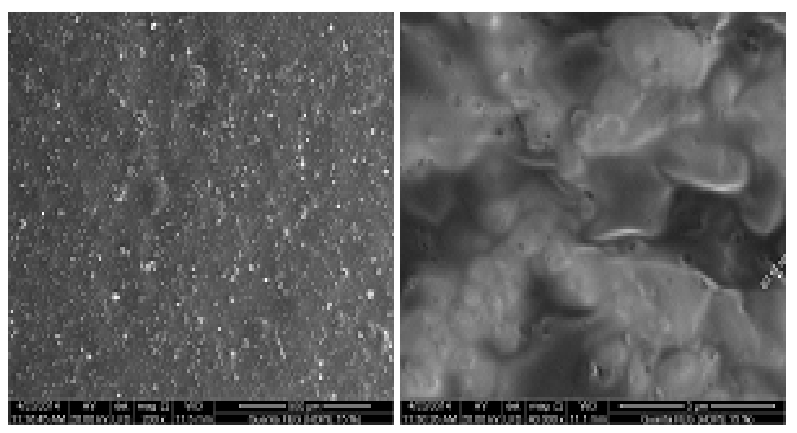

Figure 4. SEM images for HDPE $15 \%$ sample at $(200 \times \&$ 40,000×) magnifications. 
technique, the weight loss of the material due to the formation of volatile compounds under degradation because of the heating and temperature rise is monitored.

The data available from TGA is tabulated in Table 1 and graphed in Figure 5 including $\mathrm{T}_{10 \%}$ (onset temperature), the temperature at which $10 \%$ degradation from the sample occurs, $\mathrm{T}_{50 \%}$, the temperature at which $50 \%$ degradation occurs, $\mathrm{T}_{\max }$, the temperature at which maximum degradation occurs, and residual loss at $600^{\circ} \mathrm{C}$.

According to TGA results as shown in Figure 5, the incorporation of MMT to HDPE improved the thermal stability at higher degradation temperature ranges compared to pure HDPE. The temperature of the $10 \%$ degradation of HDPE 2\%, HDPE $6 \%$ and HDPE $10 \%$ has been shifted to lower temperatures relative to HDPE $0 \%$, while the $10 \%$ degradation temperature of HDPE $15 \%$ shifted to higher temperatures compared to HDPE $0 \%$. The $50 \%$ and maximum degradation temperatures have been shifted to higher temperatures compared to HDPE $0 \%$. This means that, thermal stability has been occurred with increasing the concentration of MMT composed to HDPE. The residual weight of the samples at $600^{\circ} \mathrm{C}$ increased with increasing the concentration of clay composed to HDPE. Thus, thermal stability of HDPE/clay has been improved compared to pure HDPE.

\subsection{Dielectric Properties}

\subsubsection{Dielectric Breakdown Strength}

The dielectric breakdown strength of the composites is analyzed using an AC dielectric test set at room temperature. The test was repeated 5 times for each sample and the average value was recorded and plotted as shown in Figure 6.

Figure 6 shows the behavior of the dielectric strength for HDPE/clay composites. Results show that the dielectric breakdown voltage increases with increasing the concentrations of clay-nanofiller to HDPE when compared to the pure material having the same dimensions until reaching to an optimum value (36.1 kV) at HDPE 6\% then, the breakdown voltage starts to decrease at $10 \%$, and $15 \%$ clay-nanofillers. Although the breakdown voltage decreases at $10 \%$ clay-nanofiller, its value is larger than the value of pure material. It is observed that the breakdown voltage value of the sample HDPE $15 \%$ is lower than that of pure material. As a result, the dielectric breakdown strength has been improved at all concentrations of clay-nanofiller except $15 \%$ clay concentration when compared to the unfilled material. The optimum enhancement occurred at HDPE $6 \%$.

\begin{tabular}{|ccccc|}
\hline \multicolumn{5}{c|}{ Table 1. TGA results for HDPE and HDPE/clay composites. } \\
\hline Samples & $\begin{array}{l}\mathbf{T}_{\mathbf{1} \%} \\
\left({ }^{\circ} \mathbf{C}\right)\end{array}$ & $\begin{array}{l}\mathbf{T}_{50 \%} \\
\left({ }^{\circ} \mathbf{C}\right)\end{array}$ & $\begin{array}{l}\mathbf{T}_{\max } \\
\left({ }^{\circ} \mathbf{C}\right)\end{array}$ & $\begin{array}{c}\text { Residual Weight (mg) } \\
\text { at } \mathbf{6 0 0}\end{array}$ \\
\hline HDPE 0\% & 403.6 & 451.4 & 478.3 & 0.32 \\
HDPE 2\% & 403.5 & 451.6 & 479.3 & 0.42 \\
HDPE 6\% & 396.7 & 459.0 & 481.2 & 1.24 \\
HDPE 10\% & 399.1 & 463.1 & 484.2 & 1.77 \\
HDPE 15\% & 405.3 & 464.8 & 485.1 & 4.34 \\
\hline
\end{tabular}

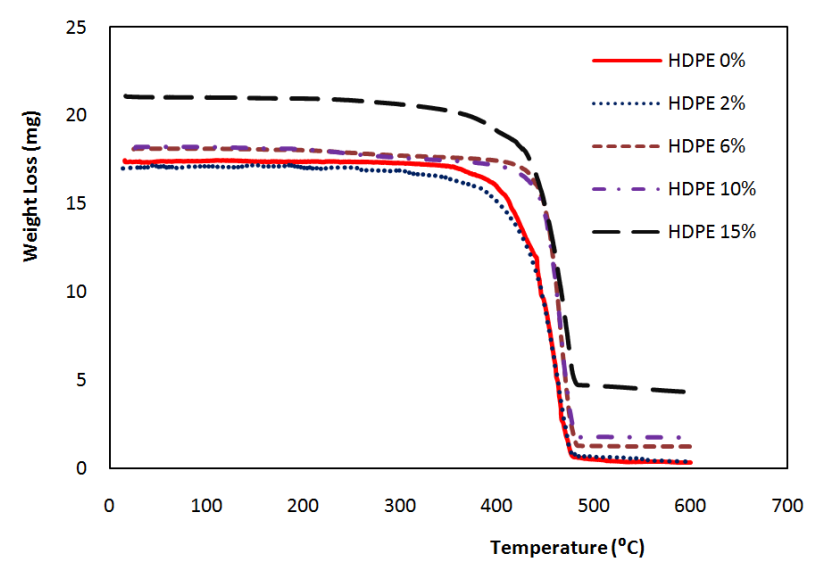

Figure 5. TGA curves for HDPE and HDPE/clay composites. 


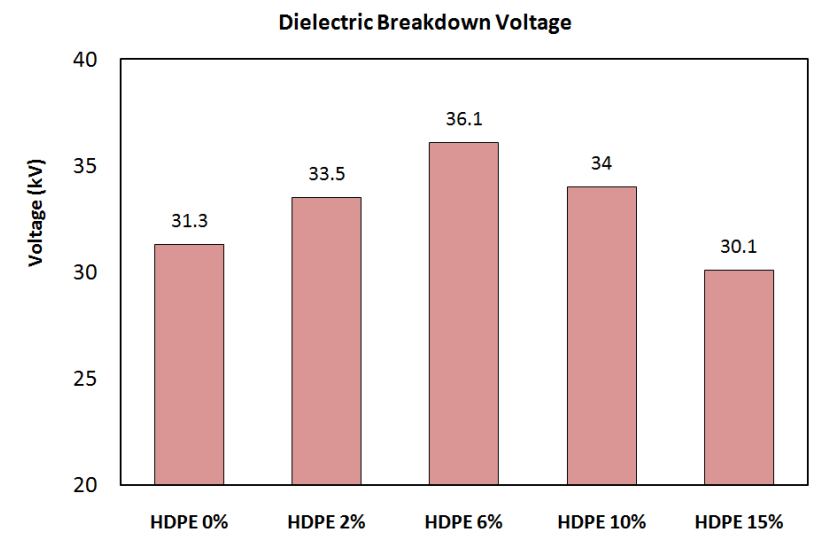

Figure 6. Dielectric breakdown strength measurement for HDPE/ clay composites.

\subsubsection{Dielectric Constant $\left(\varepsilon_{r}\right)$}

Measured quantity was the equivalent parallel capacitance $\left(C_{p}\right)$ of the samples in the frequency range of $200 \mathrm{~Hz}$ to $2 \mathrm{MHz}$, then the dielectric constant $\left(\varepsilon_{r}\right)$ was calculated by the following equations [16] and plotted as shown in Figure 7.

$$
\begin{aligned}
& C_{p}=\frac{\varepsilon_{0} \varepsilon_{r} A}{t} \\
& \varepsilon_{r}=C_{p} \frac{t}{\varepsilon_{0} A}
\end{aligned}
$$

where $\varepsilon_{0}=8.854 \times 10-12 \mathrm{~F} / \mathrm{m}$ is the permittivity of free space, $(A)$ is the area of electrodes, and $(t)$ is the thickness of the samples.

Figure 7 shows the variation of the dielectric constant $\left(\varepsilon_{r}\right)$ with frequency at room temperature for all samples. Observed differences were found in dielectric constant between pure HDPE and HDPE composites with different concentrations of clay-nanofiller. It is seen that, $\varepsilon_{r}$ decreases with increasing frequency for all samples. An important observation is that dielectric constant decreases considerably with the addition of clay-nanofiller up to $6 \%$ filler concentration, and then it starts to increase at $10 \%$ and $15 \%$ filler concentrations. The value of $\varepsilon_{r}$ at HDPE $10 \%$ is still lower than that of pure HDPE and its value at HDPE $15 \%$, is higher than the pure material. HDPE 6\% has the lowest dielectric constant and HDPE 15\% has the highest dielectric constant. The increasing of $\varepsilon_{r}$ at $10 \%$ and $15 \%$ filler concentrations may be due to the effect of $\varepsilon_{r}$ of composites (inclusions + matrix) on the resultant permittivity [17] [18]. This means that an enhancement occurred in dielectric constant at $2 \%, 6 \%$, and $10 \%$ filler concentrations when these composites used as insulating materials.

\subsubsection{Dissipation Factor (Tan $\delta$ )}

Figure 8 shows the variation of the dissipation factor (Tan $\delta$ ) with frequency at room temperature for all samples. As shown in the figure, Tan $\delta$ decreases with increasing frequency for all samples. Also an important observation is that Tan $\delta$ decreases with increasing the concentrations of clay-nanofiller incorporated in polymeric material up to $6 \%$ filler concentration, then it further increases at $10 \%$ and $15 \%$ filler concentrations. This may be due to the increasing of conductivity according to increasing of nano-filler concentration [17] [18]. HDPE 6\% has the lowest dissipation factor and HDPE $15 \%$ has the highest dissipation factor. In addition, the values of Tan $\delta$ for HDPE $2 \%$, HDPE 6\% and HDPE 10\% samples are less than that of pure material. On the other hand, the values of $\operatorname{Tan} \delta$ for $15 \%$ filler concentrations are higher than that of pure material. This means that clay-nanofiller improves the dissipation factor for HDPE polymeric material when used for insulating purpose.

\subsubsection{Insulation Resistance (R)}

Figure 9 shows the variation of the insulation resistance (R) with frequency at room temperature for all samples. Marked differences were found in the insulation resistance between pure HDPE and HDPE composites with 
different concentrations of clay-nanofiller. It is seen that, the insulation resistance decreases with increasing frequency for all samples. An important observation is that the insulation resistance increases with the addition of clay-nanofiller up to $6 \%$ filler concentration, and then it starts to decrease at $10 \%$ and $15 \%$ filler concentrations. Although that, the insulation resistance value at $10 \%$ filler concentration is still higher than that of pure HDPE. On the other hand, the insulation resistance value at $15 \%$ filler concentrations is lower than that of pure sample. The decreasing of the insulation resistance at $10 \%$ and $15 \%$ filler concentrations may be due to the increasing of conductivity of composites at high concentrations. This means that an enhancement occurred in the insulation resistance up to $10 \%$ filler concentration when compared to pure material.

Figure 10 and Figure 11 show the instruments which used for dielectric and breakdown measurements respectively.

\section{Conclusion}

HDPE/clay composites are prepared by melt compounding method (Master Batch method). Morphology structure (clay dispersion in polymer matrix and the thickness of clay-nanofiller) of the prepared samples is investigated by SEM. SEM images show that clay content is well dispersed in the polymer matrix indicating samples are successfully prepared. Thermal stability and dielectric properties are investigated for the prepared samples. TGA results show that HDPE nanocomposites have thermal stability more than unfilled polymer material. Dielectric breakdown strength is improved by the addition of clay-nanofillers. Dielectric constant and dissipation factor are studied at room temperature in the frequency range $200 \mathrm{~Hz}$ to $2 \mathrm{MHz}$. The experimental results show that there is an enhancement in both $\varepsilon_{r}$ and Tan $\delta$ due to the unique behavior of clay-nanofiller when incorpo-

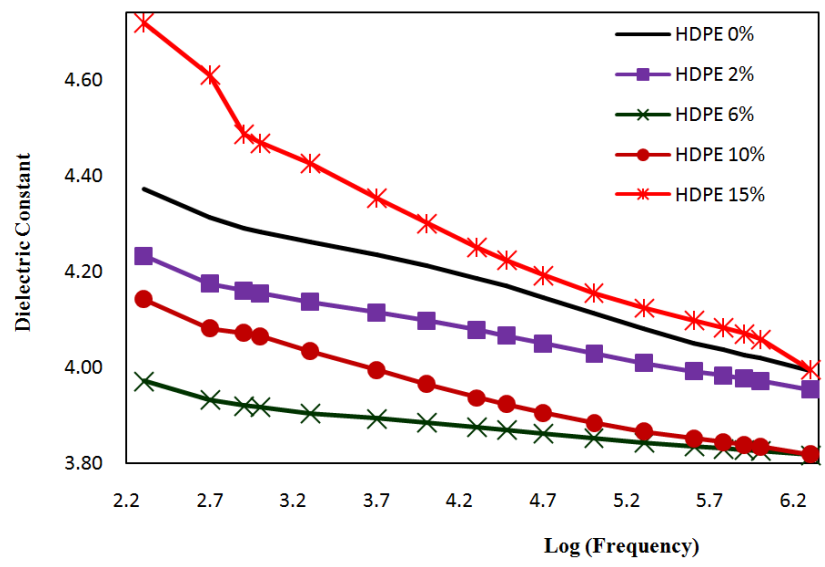

Figure 7. Frequency dependence of dielectric constant at room temperature.

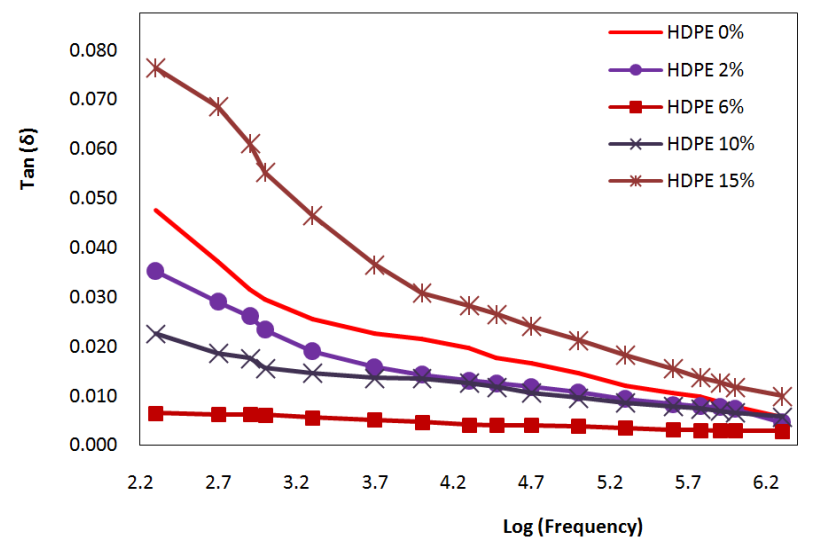

Figure 8. Frequency dependence of dissipation factor at room temperature. 


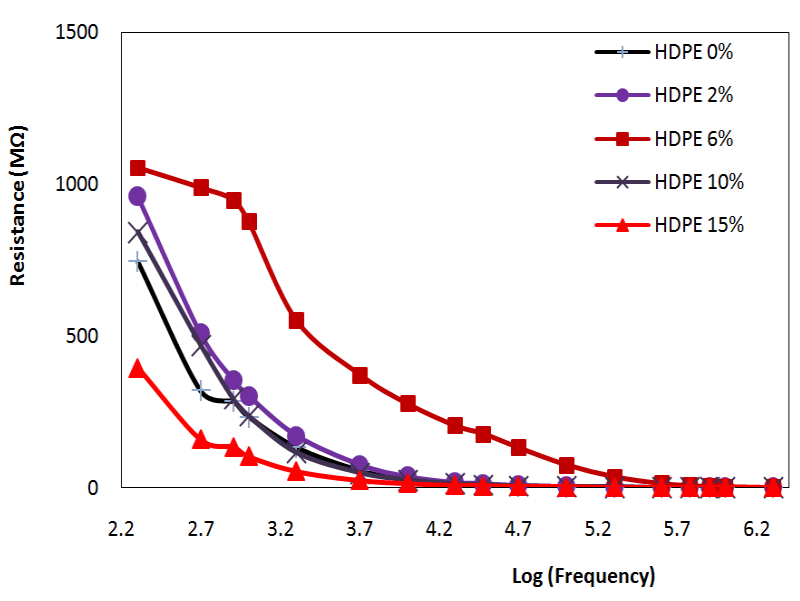

Figure 9. The insulation resistance variation with variable frequencies at room temperature.

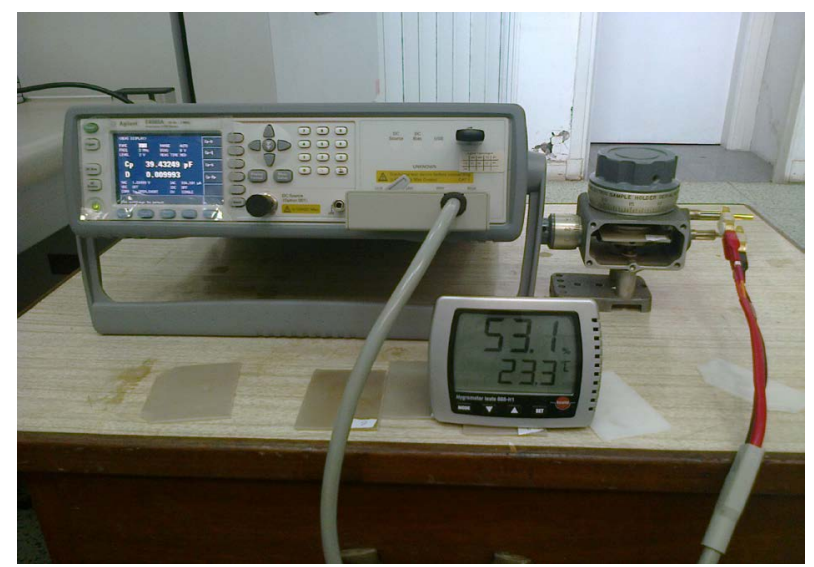

Figure 10. Agilent E4980A LCR meter with dielectric sample holder.

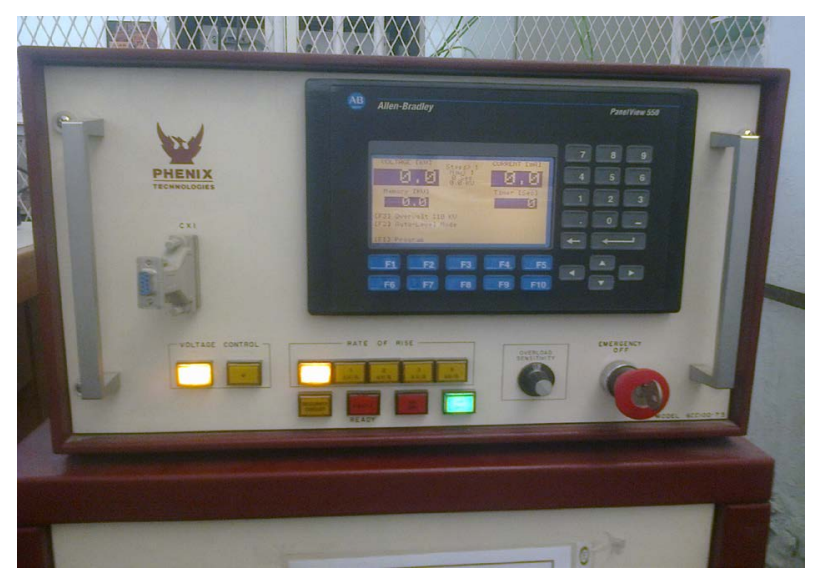

Figure 11. Dielectric test set for dielectric breakdown measurement.

rated into the polymer base matrix HDPE. Also insulation resistance has been improved by the addition of claynanofiller. From all results, it can be noticed that $6 \%$ filler concentration is the optimum clay content for HDPE/ clay system. 


\section{Acknowledgements}

The authors would like to thank the Fire and Explosion Protection Lab at NIS for giving access to the TSE facility used in this research work. The authors are also grateful to Prof. Dr. Mostafa, in Thermometry Lab at NIS, for his help in the TGA measurements.

\section{References}

[1] Du, B.X. and Liu, H.J. (2010) Effects of Atmospheric Pressure on Tracking Failure of Gamma-Ray Irradiated Polymer Insulating Materials. IEEE Transactions on Dielectrics and Electrical Insulation, 17, 541-547. http://dx.doi.org/10.1109/TDEI.2010.5448110

[2] Carmona, F. (1989) Conducting Filled Polymers. Physica A, 157, 461-469. http://dx.doi.org/10.1016/0378-4371(89)90344-0

[3] Bai, Y., Cheng, Z.-Y., Bharti, V., Xu, H.S. and Zhang, Q.M. (2000) High Dielectric-Constant Ceramic-Powder Polymer Composites. Applied Physics Letters, 76, 3804-3806. http://dx.doi.org/10.1063/1.126787

[4] Ueki, M.M. and Zanin, M. (1999) Influence of Additives on the Dielectric Strength of High-Density Polyethylene. IEEE Transactions on Dielectrics and Electrical Insulation, 6, 876-881. http://dx.doi.org/10.1109/94.822030

[5] Messersmith, P.B. and Giannelis, E.P. (1994) Synthesis and Characterization of Layered Silicate-Epoxy Nanocomposites. Chemistry of Material, 6, 1719-1725. http://dx.doi.org/10.1021/cm00046a026

[6] Ray, S.S. and Okamoto, M. (2003) Polymer/Layered Silicate Nanocomposites: A Review from Preparation to Processing. Progress in Polymer Science, 28, 1539-1641. http://dx.doi.org/10.1016/j.progpolymsci.2003.08.002

[7] Gensler, R., Groppel, P., Muhrer, V. and Muller, N. (2002) Applications of Nanoparticles in Polymers for Electronic and Electrical Engineering. Particle and Particle Systems Characterization, 19, 293-299. http://dx.doi.org/10.1002/1521-4117(200211)19:5<293::AID-PPSC293>3.0.CO;2-N

[8] Tanaka, T. (2005) Dielectric Nanocomposites with Insulating Properties. IEEE Transactions on Dielectrics and Electrical Insulation, 12, 914-928. http://dx.doi.org/10.1109/TDEI.2005.1522186

[9] Cao, Y., Irwin, P.C. and Younsi, K. (2004) The Future of Nanodielectrics in the Electrical Power Industry. IEEE Transactions on Dielectrics and Electrical Insulation, 11, 797-807. http://dx.doi.org/10.1109/TDEI.2004.1349785

[10] Imai, T., Sawa, F., Ozaki, T., Inoue, Y., Shimizu, T. and Tanaka, T. (2006) Comparison of Insulation Breakdown Properties of Epoxy Nanocomposites under Homogeneous and Divergent Electric Fields. 2006 IEEE Conference on Electrical Insulation and Dielectric Phenomena, Kansas, 15-18 October 2006, 306-309. http://140.98.202.196/xpl/login.jsp?tp=\&arnumber=4105431\&url=http\%3A\%2F\%2F140.98.202.196\%2Fstamp\%2Fsta mp.jsp\%3Ftp\%3D\%26arnumber\%3D4105431

[11] Lewis, T.J. (2004) Interfaces Are the Dominant Feature of Dielectrics at the Nanometric Level. IEEE Transactions on Dielectrics and Electrical Insulation, 11, 739-753. http://dx.doi.org/10.1109/TDEI.2004.1349779

[12] Roy, M., Nelson, J.K., MacCrone, R.K. and Schadler, L.S. (2005) Polymer Nanocomposite Dielectrics-The Role of the Interface. IEEE Transactions on Dielectrics and Electrical Insulation, 12, 629-643. http://dx.doi.org/10.1109/TDEI.2005.1511089

[13] Ajayan, P.M., Schadler, L.S. and Braun, P.V. (2003) Nanocomposite Science and Technology. John Wiley \& Sons Inc., New York. http://dx.doi.org/10.1002/3527602127

[14] Liu, X.H. and Wu, Q.J. (2001) PP/Clay Nanocomposites Prepared by Grafting-Melt Intercalation. Elsevier Polymer, 42, 10013-10019. http://dx.doi.org/10.1016/S0032-3861(01)00561-4

[15] Hassan, M.A., El-Sayed, I., Nour, M.A. and Mohamed, A.A. (2012) Flammability Properties of HDPE Nanocomposites Based on Modification of Na-MMT with Organo Silane and Ammonium Phosphate Mono and Di Basic. Elixir Applied Chemistry, 46, 8328-8333. http://www.elixirpublishers.com/index.php?route=articles/category\&path=305 306\&page=9

[16] Li, L. (2011) Dielectric Properties of Aged Polymers and Nanocomposites. Ph.D. Thesis, Iowa State University, Iowa.

[17] Singha, S. and Thomas, M.J. (2008) Permittivity and Tan Delta Characteristics of Epoxy Nanocomposites. IEEE Transactions on Dielectrics and Electrical Insulation, 15, 2-11. http://dx.doi.org/10.1109/T-DEI.2008.4446731

[18] Singha, S. and Thomas, M.J. (2008) Dielectric Properties of Epoxy Nanocomposites. IEEE Transactions on Dielectrics and Electrical Insulation, 15, 12-23. http://dx.doi.org/10.1109/T-DEI.2008.4446732 
Scientific Research Publishing (SCIRP) is one of the largest Open Access journal publishers. It is currently publishing more than 200 open access, online, peer-reviewed journals covering a wide range of academic disciplines. SCIRP serves the worldwide academic communities and contributes to the progress and application of science with its publication.

Other selected journals from SCIRP are listed as below. Submit your manuscript to us via either submit@scirp.org or Online Submission Portal.
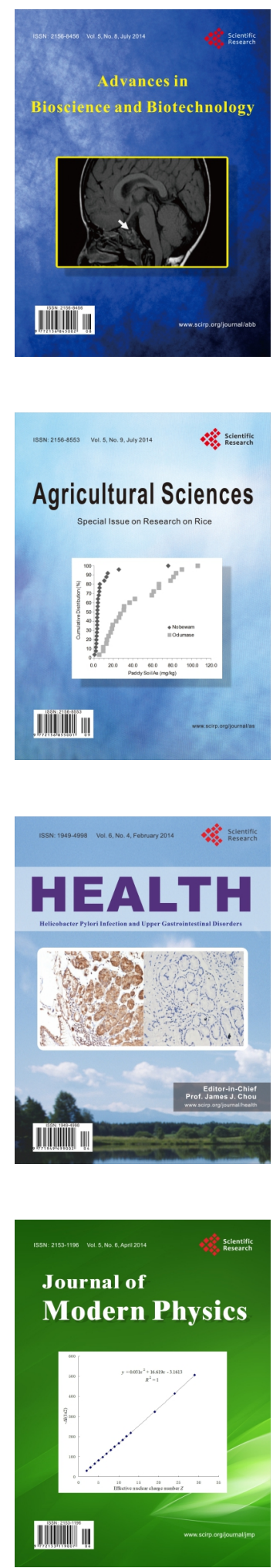
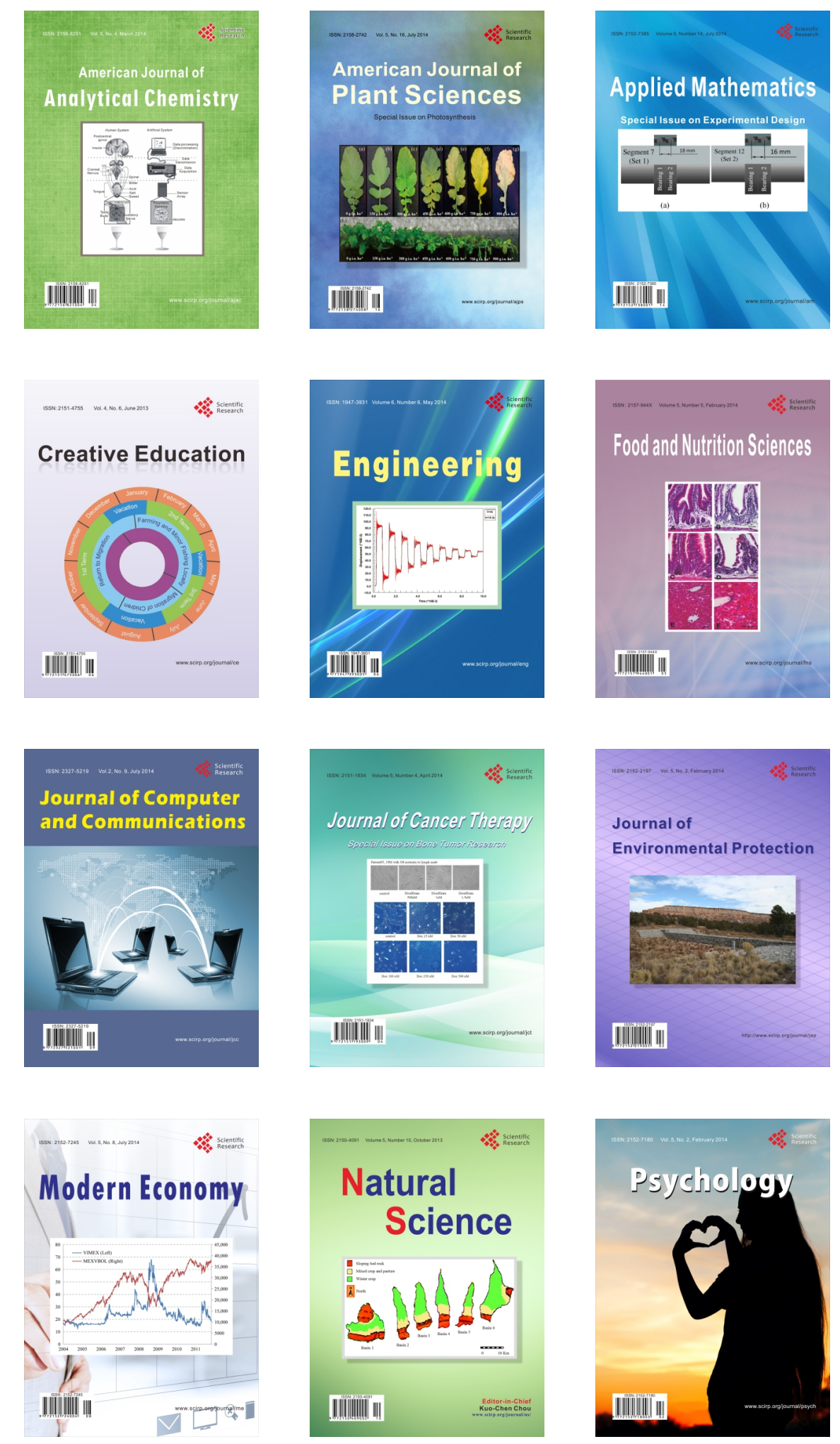